\title{
Synthesis, Crystal Structure, and Magnetic Properties of the Oxometallates $\mathrm{KBaMnO}_{4}$ and $\mathrm{KBaAsO}_{4}$
}

Karl D. zur Loye, W. Michael Chance, Jeongho Yeon, Hans-Conrad zur Loye*

Department of Chemistry and Biochemistry, University of South Carolina, Columbia, SC 29208, USA

* To whom correspondence should be addressed

Hans-Conrad zur Loye

TEL: $+1-803-777-6916$

FAX: $+1-803-777-8508$

zurloye@mailbox.sc.edu 


\title{
Synthesis, Crystal Structure, and Magnetic Properties of the Oxometallates $\mathrm{KBaMnO}_{4}$ and $\mathrm{KBaAsO}_{4}$
}

Karl D. zur Loye, W. Michael Chance, Jeongho Yeon, Hans-Conrad zur Loye*

\begin{abstract}
Single crystals of $\mathrm{KBaMnO}_{4}$ and $\mathrm{KBaAsO}_{4}$ were grown using the hydroflux method and characterized by single crystal X-ray diffraction. Both compounds crystallize in the orthorhombic space group Pnma with $a=7.7795(4) \AA, b=5.8263(3) \AA$, and $c=10.2851(5) \AA$ for the manganate and $a=7.7773(10) \AA$, $b=5.8891(8) \AA$, and $c=10.3104(13) \AA$ for the arsenate. The materials exhibit a threedimensional crystal structure consisting of isolated $\mathrm{MnO}_{4}{ }^{3-}$ or $\mathrm{AsO}_{4}{ }^{3-}$ tetrahedra, with the charge balance maintained by $\mathrm{K}^{+}$and $\mathrm{Ba}^{2+}$. Each tetrahedron is surrounded by six $\mathrm{K}^{+}$and five $\mathrm{Ba}^{2+}$, and shares its corner/edge with $\mathrm{KO}_{10}$ polyhedra and corner/edge/face with $\mathrm{BaO}_{9}$ polyhedra, respectively. The crystal growth, crystal structure and magnetic properties are discussed.
\end{abstract}

Keywords Crystal growth - Crystal Structure - Magnetism $\cdot$ Hydroflux $\cdot \mathrm{KBaMnO}_{4}$. $\mathrm{KBaAsO}_{4}$ 


\section{Introduction}

The ability to crystallize and characterize new materials often depends on the availability of an appropriate synthetic method for the compositions of interest. Hence, developing new methods for growing single crystals are of general interest, especially if they permit the exploration of chemical systems that previously have proven difficult to obtain. Arsenates and manganates $\left(\mathrm{Mn}^{5+}\right)$ are examples of classes of materials that have proven difficult to prepare using typical crystal growth approaches.

Pentavalent manganese is rare in extended structures. $\mathrm{Mn}^{5+}$ was first prepared in a complex oxide by Lux from strong alkali solutions[1]. Most $\mathrm{Mn}^{5+}$ compounds previously synthesized were prepared by the solid state method under $\mathrm{O}_{2}$ flow near $1000{ }^{\circ} \mathrm{C}[2-4]$. More recent investigations have prepared manganates via low temperature routes such as hydrothermal synthesis or flux growth. Much of the literature has focused on the intense colors exhibited by $\mathrm{Mn}^{5+}$ compounds[5], while other investigations have focused on the near infrared emission of manganates and their potential use in laser materials[6]. More recent studies of the magnetic properties of $\mathrm{Ba}_{3} \mathrm{Mn}_{2} \mathrm{O}_{8}$ have brought renewed interest in the magnetic properties of solids containing $\mathrm{Mn}^{5+}[7-10]$.

Arsenates have recently raised environmental concerns when they are found in ground water and significant research has focused on methods to remove arsenic from water[11]. In solid-state chemistry, arsenates have been identified as useful building blocks for inorganic framework materials, such as MOFs and zeolites, where the $\mathrm{AsO}_{4}{ }^{3-}$ unit can sometimes be used in place of phosphate, $\mathrm{PO}_{4}{ }^{3-}[12]$.

Hydroflux synthesis offers a reaction media that bridges the gap between wet hydroxide fluxes and aqueous hydroxide reactions and represents a simple approach for exploratory crystal growth. The typical operating temperature for a hydroflux ranges from $200-240^{\circ} \mathrm{C}$, significantly less that temperatures used for typical hydroxide flux crystal growth $\left(500-850^{\circ} \mathrm{C}\right)$, and comparable to the temperatures used for mild hydrothermal crystal growth. An added advantage of the hydroflux is the absence of high pressure, simplifying the experimental set up. Previously, we have demonstrated the utility of hydrofluxes for the crystal growth of both hydroxides and oxides[13-15]. We sought to determine if the hydroflux approach to crystal growth could be extended to main group elements and become a route to growing arsenate single crystals. Using this 
approach, we were able to prepare both manganates and arsenates, $\mathrm{KBaMnO}_{4}$ and $\mathrm{KBaAsO}_{4}$, single crystals out of a potassium hydroxide hydroflux. Herein, we report on the synthesis and crystal structure of the new arsenate $\mathrm{KBaAsO}_{4}$ and the crystal structure, optical and magnetic properties of $\mathrm{KBaMnO}_{4}$.

\section{Experimental Details}

\subsection{Crystal Growth}

Single crystals of $\mathrm{KBaAsO}_{4}$ were grown out of a hydroflux of potassium hydroxide containing approximately $33 \%$ water by weight. The reaction was carried out in a $23 \mathrm{~mL}$ polytetrafluoroethylene (PTFE) lined stainless steel autoclave. A mixture of $0.75 \mathrm{mmol}$ of $\mathrm{As}_{2} \mathrm{O}_{3}\left(0.1320 \mathrm{~g}\right.$ ) (Alfa Aesar, 99.95\%), $1 \mathrm{mmol}$ of $\mathrm{Ba}\left(\mathrm{NO}_{3}\right)_{2}(0.2614 \mathrm{~g}$ ) (Alfa Aesar, 99.95\%), $8 \mathrm{~g}$ of $\mathrm{KOH}$ (VWR, 85\%), and $4 \mathrm{ml}$ of deionized water were added to the autoclave, which was sealed. The autoclave was heated to $230^{\circ}$ at $5^{\circ} \mathrm{C} /$ minute, held for 24 hours, and then cooled slowly to $33^{\circ} \mathrm{C}$ at a rate of $0.3^{\circ} /$ minute, at which point the oven was shut off. After cooling, the liquid in the autoclave was poured out, and the crystals inside were dislodged from the sides and rinsed out of the autoclave with methanol.

Single crystals of $\mathrm{KBaMnO}_{4}$ were grown from a mixed $\mathrm{NaOH} / \mathrm{KOH}$ hydroflux. Crystal growth was carried out in a custom fabricated, virgin PTFE vessel with $\sim 23 \mathrm{~mL}$ total volume. No secondary containment was necessary for pressure. $1.5 \mathrm{mmols}$ of $\mathrm{Ba}(\mathrm{OH})_{2} \bullet 8 \mathrm{H}_{2} \mathrm{O}$ (Alfa Aesar, 99+\%) and $1 \mathrm{mmol}$ of $\mathrm{KMnO}_{4}$ (Fisher Scientific, ACS Grade) were added to a hydroflux made from $5.6 \mathrm{~g}$ of $\mathrm{KOH}$ (Fisher Scientific, ACS grade pellets) $4.3 \mathrm{~g}$ of $\mathrm{NaOH}$ (Fisher Scientific, ACS grade pellets) and $4 \mathrm{~g}$ of water. The reaction mixtures were heated to $230{ }^{\circ} \mathrm{C}$ at $5^{\circ} \mathrm{C}$ per minute and held for 12 hours before being cooled at a rate of $0.3{ }^{\circ} \mathrm{C}$ per minute to $80 \mathrm{C}$.

\subsection{Single Crystal X-Ray Diffraction}

X-ray intensity data from single crystals of $\mathrm{KBaMnO}_{4}$ and $\mathrm{KBaAsO}_{4}$ were collected at 298(2) K using a Bruker SMART APEX diffractometer (Mo K $\alpha$ radiation, $\lambda$ $=0.71073 \AA$ ) [16]. The raw area detector data frames were reduced with SAINT+[16]. Data were corrected for absorption effects using the multi-scan technique implemented in 
SADABS[16]. The reported unit cell parameters were determined by least-squares refinement of large sets of strong reflections taken from each data set. Full-matrix leastsquares refinement against $\mathrm{F}^{2}$ of the structural models and difference Fourier calculations were performed with SHELXTL[17]. Detailed crystallographic data and selected interatomic distances are reported in Tables 1,2, and 3.

\subsection{Energy-Dispersive Spectroscopy (EDS)}

Elemental analysis was performed on the crystals using a Tescan Vega 3 scanning electron microscope (SEM) with EDS capabilities. The crystals were mounted on carbon tape and analyzed using a $30 \mathrm{kV}$ accelerating voltage and an accumulation time of $15 \mathrm{~s}$. As a qualitative measure, the EDS confirmed the presence of each element and corroborated the approximate elemental ratios.

\subsection{Magnetic Susceptibility Measurements}

The DC magnetic susceptibility of $\mathrm{KBaMnO}_{4}$ was measured as a function of temperature using a Quantum Design MPMS SQUID VSM. For a typical temperature sweep experiment, the sample was first cooled to $2 \mathrm{~K}$ under zero-field cooled (zfc) conditions and data were collected upon warming to $300 \mathrm{~K}$ in an applied field of 1000 Oe. Data were then collected under field cooled cooling (fcc) from $300 \mathrm{~K}$ to $2 \mathrm{~K}$ in an applied field of 1000 Oe. Radial offset and sample shape corrections were applied to the magnetization data using a fitting routine involving data collected at $30 \mathrm{~K}$ under both DC and VSM modes[18].

\section{Results and Discussion}

Synthesis. Single crystals of $\mathrm{KBaAsO}_{4}$ were grown out of a hydroflux of potassium hydroxide containing approximately $33 \%$ water by weight at $230^{\circ} \mathrm{C}$ for 24 hours. The colorless, well faceted polyhedral crystals were obtained in essentially quantitative yield as a phase pure product. (Figure 1) The crystals were isolated by decanting the liquid hydroflux and by washing the crystals quickly with methanol. Phase

pure samples of $\mathrm{KBaMnO}_{4}$ crystals were obtained from hydroflux synthesis with a yield of $72 \%$ (Figures 2 and 3) using the experimental conditions detailed herein. Initially, 
crystals were grown from an open atmosphere reaction in a PTFE cup on a hot plate with the same hydroflux composition. Crystal quality was greatly increased by switching to sealed vessels and slow cooling in an oven. After cooling to room temperature, the solid hydroflux was still green after the reaction, indicating the incomplete reaction of $\mathrm{MnO}_{4}{ }^{3-}$. Crystals were isolated by sonication in methanol. Small amounts of $\mathrm{BaCO}_{3}$ were also formed and removed with a sieve. The single crystal structures were determined and both compounds were found to be isostructural with $\mathrm{KBaVO}_{4}$ and are members of the Arcanite family, named after the mineral $\mathrm{K}_{2} \mathrm{SO}_{4}$.

Crystal Structure. The $\beta-\mathrm{K}_{2} \mathrm{SO}_{4}$ structure type $\left(\mathrm{A}_{2} \mathrm{MO}_{4}\right)$, including structural variants, is often observed for oxometallates and simple salts such as $\mathrm{Tl}_{2} \mathrm{SO}_{4}$, $\mathrm{Ba}_{2} \mathrm{TiO}_{4}$ [19], $\mathrm{Ba}_{2} \mathrm{CoO}_{4}\left[20\right.$ ], $\mathrm{Ba}_{2} \mathrm{CrO}_{4}[21], \mathrm{K}_{2} \mathrm{CrO}_{4}\left[22\right.$ ], and $\mathrm{Tl}_{2} \mathrm{CrO}_{4}$ [23]. More complex compositions, namely those containing two cations $\left(\mathrm{AA}^{\prime} \mathrm{MO}_{4}\right)\left(\mathrm{A}=\mathrm{Na}, \mathrm{K} ; \mathrm{A}^{\prime}=\mathrm{Sr}, \mathrm{Ba}\right)$ are found among the phosphates and vanadates, such as $\mathrm{KBaPO}_{4}$ [24], $\mathrm{KBaVO}_{4}$ [25], and some structurally related phases are found among the aluminates and gallates, including $\mathrm{BaLaAlO}_{4}[26]$ and $\mathrm{BaLaGaO}_{4}[27]$.

$\mathrm{KBaMnO}_{4}$ and $\mathrm{KBaAsO}_{4}$ crystallize in the orthorhombic space group Pnma. The structure, shown in Figure 4, consists of isolated $\mathrm{MnO}_{4}{ }^{3-}$ or $\mathrm{AsO}_{4}{ }^{3-}$ tetrahedra with the charge balance maintained by $\mathrm{K}^{+}$and $\mathrm{Ba}^{2+}$ cations. Each tetrahedron is surrounded by six $\mathrm{K}^{+}$and five $\mathrm{Ba}^{2+}$ cations, and shares its corner/edge with $\mathrm{KO}_{10}$ polyhedra and corner/edge/face with $\mathrm{BaO}_{9}$ polyhedra, respectively. The $\mathrm{KO}_{10}$ polyhedra are connected to each other via face-sharing along the $b$-axis and corner/edge-sharing in the $a c$-plane. One interesting structural feature is the presence of hexagonal channels, created by the arrangement of the $\mathrm{KO}_{10}$ polyhedra, along the $a$-axis, which contain $\mathrm{Ba}^{2+}$ cations. (Figure 5) The $\mathrm{BaO}_{9}$ polyhedra share their face, corner, and edge along the $a-, b$-, and $c$-axes, respectively, forming a 3D structure. The $\mathrm{Mn}-\mathrm{O}$ bond distances in the $\mathrm{MnO}_{4}$ tetrahedra range from $1.680(5) \AA$ to $1.692(4) \AA$, and the As-O bond distances in the $\mathrm{AsO}_{4}$ tetrahedron range from $1.680(5) \AA$ to $1.692(4) \AA$, both of which fall into the normal bond length ranges observed in the literature. Both $\mathrm{K}^{+}$and $\mathrm{Ba}^{2+}$ cations are observed in irregular polyhedra with distances to oxygen atoms of 2.774(5) - 3.205(4) and 2.688(4) 3.133(2) for $\mathrm{KO}_{10}$ and $\mathrm{BaO}_{9}$ polyhedra in the manganese analog and 2.713(5) - 3.273(4) and 2.680(3) - 3.205(2) for $\mathrm{KO}_{10}$ and $\mathrm{BaO}_{9}$ polyhedra in the arsenic analog, respectively. 
Bond Valence Analysis. Bond valence sum calculations were performed for both compounds on an Excel spreadsheet using bond valence parameters by Brown[28]. For $\mathrm{KBaAsO}_{4}$, bond valence sums of 2.11, 0.82, and 5.02 for barium, potassium, and arsenic, respectively, are in good agreement with the expected values for $\mathrm{Ba}^{2+}, \mathrm{K}^{+}$and $\mathrm{As}^{5+}$. For $\mathrm{KBaMnO}_{4}$, bond valence sum calculations yielded values of 2.20 and 0.87 for barium and potassium, respectively. These values are in good agreement with the expected oxidation states for $\mathrm{Ba}^{2+}$ and $\mathrm{K}^{+}$. There is no bond valence parameter listed for $\mathrm{Mn}^{5+}$. However, using the parameter for $\mathrm{Mn}^{6+}$ (1.79) yields a bond valence sum for manganese of 5.20, consistent with what is expected based on the phase composition.

Magnetism. The temperature dependence of the magnetic susceptibility $(\chi)$ for $\mathrm{KBaMnO}_{4}$ was measured under zfc and fcc conditions. A sample consisting of ground crystals, phase pure by powder X-ray diffraction, was used for the magnetic measurements. The temperature dependence of the inverse susceptibility data were fit to the Curie-Weiss law where $\chi=C /(\mathrm{T}-\theta)$, where $C$ is the Curie constant, and $\theta$ is the Weiss temperature. $\mathrm{KBaMnO}_{4}$ exhibits an effective magnetic moment of $2.74 \mu_{\mathrm{B}}$, in good agreement with the moment expected for $\mathrm{Mn}^{5+}\left(\mu_{\mathrm{eff}}=2.83 \mu_{\mathrm{B}}, S=1\right)$. (Figures 6 and 7) The data indicate antiferromagnetic interactions at low temperature and a maximum in the magnetic susceptibility is observed at $4.16 \mathrm{~K}$, consistent with an observed Weiss constant of $-4.86 \mathrm{~K}$. A Nèel temperature, defined as the peak in the $\mathrm{d} \chi \mathrm{T} / \mathrm{dT}$ plot [29], of $3.64 \mathrm{~K}$ can be extracted from the magnetic susceptibility data, which is reasonably low considering that the shortest manganese-manganese distance in $\mathrm{KBaMnO}_{4}$ is $4.97 \AA$.

\section{Conclusion}

Crystals of $\mathrm{KBaMnO}_{4}$ and $\mathrm{KBaAsO}_{4}$ have been grown for the first time using a low temperature hydroflux method. These compounds take on the Arcanite or $\beta-\mathrm{K}_{2} \mathrm{SO}_{4}$ structure type. The $\mathrm{KBaAsO}_{4}$ crystals are clear and colorless, while the $\mathrm{KBaMnO}_{4}$, crystals have a deep green color due to the presence of $\mathrm{Mn}^{5+}$. The optical properties of $\mathrm{KBaMnO}_{4}$ are reported. The magnetic properties of $\mathrm{KBaMnO}_{4}\left(\mathrm{Mn}^{5+} ; \mathrm{d}^{2}\right)$ have been investigated and $\mathrm{KBaMnO}_{4}$ was found to order antiferromagnetically with a Néel temperature of $3.64 \mathrm{~K}$. 


\section{Acknowledgments}

This work was supported in part by HeteroFoaM, an Energy Frontier Research Center funded by the U.S. Department of Energy, Office of Science, and Office of Basic Energy Sciences under Award Number DE-SC0001061 and in part by the National Science Foundation through grant DMR-1301757. Mary Anne Fitzpatrick, Dean, and the USC selection committee are gratefully acknowledged for supporting Michael Chance via a College of Arts and Sciences Dean's Dissertation Fellowship.

\section{References}

[1] H. Lux, Z. Naturforsch. 1 (1946) 281-283.

[2] K. Dardenne, D. Vivien, D. Huguenin, J. Solid State Chem. 146 (1999) 464-472.

[3] D. A. Grisafe, F. A. Hummel, J. Solid State Chem. 2 (1970) 160-166.

[4] P. Jiang, Li, J., Ozarowski, A., Sleight, A. W., Subramanian, M. A. Inorg. Chem. 52 (2013) 1349-1357.

[5] D. Reinen, W. Rauw, U. Kesper, M. Atanasov, H.U. Güdel, M. Hazenkamp, U. Oetliker, J. of Alloys Comp. 246 (1997) 193.

[6] L. D. Merkle, Y. Guyot, B. H. T. Chai, J. Appl. Phys. 577 (1995) 474.

[7] M. B. Stone, M. D. Lumsden, Y. Qiu, E. C. Samulon, C. D. Batista, and I. R. Fisher, Phys. Rev. B 77 (2008) 134406.

[8] H. Tsujii, B. Andraka, M. Uchida, H. Tanaka, and Y. Takano, Phys. Rev. B 72 (2005) 214434.

[9] M. Uchida, H. Tanaka, M. I. Bartashevich, T. J. Goto, Phys. Soc. Jap. 70 (2001) 1790-1793.

[10] M. Uchida, H. Tanaka, H. Mitamura, F. Ishikawa, T. Goto, Phys. Rev. B 66 (2002) 054429.

[11] I. Villaescusa, J.-C. Bollinger, Rev. Environ. Sci. Biotechnol. 7 (2008) 307.

[12] S. Natarjan, S. Mandal, Angew. Chem., Int. Ed. 47 (2008) 4798.

[13] D. E. Bugaris, M. D. Smith, H.-C. zur Loye, Inorg. Chem. 52 (2013) 3836-3844.

[14] W. M. Chance, D. E. Bugaris, A. S. Sefat, H.-C. zur Loye, Inorg. Chem. 52 (2013) 11723-11733.

[15] W. M. Chance, H.-C. zur Loye, Solid State Sci. 28 (2014) 90-94.

[16] SMART Version 5.631, SAINT+ Version 6.45 and SADABS Version 2.10, Bruker 
Analytical X-ray Systems, Inc., Madison, Wisconsin, USA, 2003

[17] SHELXTL Version 6.14, Bruker analytical X-ray Systems, Inc., Madison, WI, 2000

[18] G. Morrison, H.-C. zur Loye, Submitted (2014)

[19] J. A. Bland Acta Crystallogr. 14 (1961) 875.

[20] H. Mattausch, H. Müller- Buschbaum,. Anorg. Allg. Chem. 386 (1971) 1.

[21] H. Mattausch, H. Müller-Buschbaum, Z. Anorg. Allg. Chem. 407 (1974) 129.

[22] G. Liu, J. E. Greedan, W. J. Gong, Solid State Chem. 105 (1993) 78.

[23] R. L. Carter, T. N. Margulis, J. Solid State Chem. 5 (1972) 75.

[24] C. W. Struck, J. G. White, Acta Crystalogr. 15 (1962) 290.

[25] H. Müller-Buschbaum, O. Z. Schrandt, Naturforsch. 51b (1996) 477.

[26] L. M. Kovba, L. N. Lykova, E. V. Antipov, Koord. Khim. 11 (1985) 1574.

[27] I. Rüter, H. Müller-Buschbaum, Z. Anorg. Allg. Chem. 584 (1990) 119.

[28] I. D. Brown, The Chemical Bond in Inorganic Chemistry: The Bond Valence Model; Oxford University Press: 2006.

[29] M. Fisher, Phil. Mag. 7 (1962) 1731. 
Table 1 Crystallographic data for $\mathrm{KBaMO}_{4}(M=\mathrm{Mn}, \mathrm{As})$.

\begin{tabular}{|c|c|c|}
\hline formula & $\mathrm{KBaMnO}_{4}$ & $\mathrm{KBaAsO}_{4}$ \\
\hline formula weight & 295.38 & 315.36 \\
\hline temperature $(\mathrm{K})$ & $298(2)$ & $298(2)$ \\
\hline color and habit & blue/green, polyhedral & colorless, polyhedral \\
\hline crystal system & Orthorhombic & Orthorhombic \\
\hline space group & $P n m a$ & $P n m a$ \\
\hline$a(\AA)$ & $7.7795(4)$ & $7.7773(10)$ \\
\hline$b(\AA)$ & $5.8263(3)$ & $5.8891(8)$ \\
\hline$c(\AA)$ & $10.2851(5)$ & $10.3104(13)$ \\
\hline$V\left(\AA^{3}\right)$ & $466.18(4)$ & $472.23(11)$ \\
\hline$Z$ & 4 & 4 \\
\hline$\rho_{c}\left(\mathrm{~g} \mathrm{~cm}^{-3}\right)$ & 4.209 & 4.436 \\
\hline$\mu\left(\mathrm{mm}^{-1}\right)$ & 11.884 & 16.136 \\
\hline$F(000)$ & 528 & 560 \\
\hline crystal size $\left(\mathrm{mm}^{3}\right)$ & $0.15 \times 0.08 \times 0.03$ & $0.09 \times 0.06 \times 0.06$ \\
\hline 2 theta range $\left(^{\circ}\right)$ & 6.56 to 56.54 & 6.56 to 56.60 \\
\hline completeness $(\%)$ & 100 & 100 \\
\hline reflections collected & 5970 & 5146 \\
\hline independent reflections & 632 & 643 \\
\hline$R$ (int) & 0.0302 & 0.0199 \\
\hline $\operatorname{GOF}\left(F^{2}\right)$ & 1.172 & 1.213 \\
\hline$R(F)^{a}$ & 0.0245 & 0.0223 \\
\hline$R_{\mathrm{w}}\left(F_{\mathrm{o}}^{2}\right)^{b}$ & 0.0684 & 0.0607 \\
\hline Largest diff. peak and hole (e $\left.\AA^{-3}\right)$ & 1.691 and -0.672 & 0.750 and -1.413 \\
\hline
\end{tabular}


Table 2 Atomic coordinates and equivalent isotropic displacement parameters $U_{\text {eq }}$ for $\mathrm{KBaMO}_{4}(M=\mathrm{Mn}, \mathrm{As}) . U_{\text {eq }}$ is defined as one third of the trace of the orthogonalized $U_{\mathrm{ij}}$ tensor.

\begin{tabular}{|c|c|c|c|c|}
\hline & $\mathrm{x}$ & $\mathrm{y}$ & $\mathrm{z}$ & $U_{\text {eq }}$ \\
\hline \multicolumn{5}{|c|}{$\mathrm{KBaMnO}_{4}$} \\
\hline $\mathrm{Ba}(1)$ & $0.5093(1)$ & 0.25 & $0.3070(1)$ & $0.015(1)$ \\
\hline $\mathrm{K}(1)$ & $0.8416(2)$ & 0.25 & $0.5833(2)$ & $0.015(1)$ \\
\hline $\operatorname{Mn}(1)$ & $0.2677(1)$ & 0.25 & $0.5819(1)$ & $0.011(1)$ \\
\hline $\mathrm{O}(1)$ & $0.1941(7)$ & 0.25 & $0.4265(5)$ & $0.017(1)$ \\
\hline $\mathrm{O}(2)$ & $0.1973(5)$ & $0.0105(6)$ & $0.6582(4)$ & $0.022(1)$ \\
\hline $\mathrm{O}(3)$ & $0.4851(6)$ & 0.25 & $0.5809(6)$ & $0.023(1)$ \\
\hline \multicolumn{5}{|c|}{$\mathrm{KBaAsO}_{4}$} \\
\hline $\mathrm{Ba}(1)$ & $0.5052(1)$ & 0.25 & $0.3007(1)$ & $0.014(1)$ \\
\hline $\mathrm{K}(1)$ & $0.8352(2)$ & 0.25 & $0.5816(1)$ & $0.019(1)$ \\
\hline $\operatorname{As}(1)$ & $0.2707(1)$ & 0.25 & $0.5819(1)$ & $0.011(1)$ \\
\hline $\mathrm{O}(1)$ & $0.1916(6)$ & 0.25 & $0.4290(4)$ & $0.019(1)$ \\
\hline $\mathrm{O}(2)$ & $0.2026(4)$ & $0.0156(5)$ & $0.6593(3)$ & $0.021(1)$ \\
\hline $\mathrm{O}(3)$ & $0.4865(6)$ & 0.25 & $0.5768(5)$ & $0.025(1)$ \\
\hline
\end{tabular}




\section{Table 3}

Selected interatomic distances $(\AA)$ for $\mathrm{KBaMO}_{4}(M=\mathrm{Mn}, \mathrm{As})$.

\begin{tabular}{lll}
\hline & $\mathrm{KBaMnO}_{4}$ & $\mathrm{KBaAsO}_{4}$ \\
\hline $\mathrm{Ba}(1)-\mathrm{O}(2)$ & $2.680(3)$ & $2.688(4)$ \\
$\mathrm{Ba}(1)-\mathrm{O}(2)$ & $2.680(3)$ & $2.688(4)$ \\
$\mathrm{Ba}(1)-\mathrm{O}(1)$ & $2.774(4)$ & $2.742(5)$ \\
$\mathrm{Ba}(1)-\mathrm{O}(1)$ & $2.777(4)$ & $2.764(4)$ \\
$\mathrm{Ba}(1)-\mathrm{O}(2)$ & $2.790(3)$ & $2.764(4)$ \\
$\mathrm{Ba}(1)-\mathrm{O}(2)$ & $2.790(3)$ & $2.799(5)$ \\
$\mathrm{Ba}(1)-\mathrm{O}(3)$ & $2.850(5)$ & $2.823(6)$ \\
$\mathrm{Ba}(1)-\mathrm{O}(3)$ & $3.205(2)$ & $3.133(2)$ \\
$\mathrm{Ba}(1)-\mathrm{O}(3)$ & $3.205(2)$ & $3.133(2)$ \\
$\mathrm{K}(1)-\mathrm{O}(3)$ & & \\
$\mathrm{K}(1)-\mathrm{O}(2)$ & $2.713(5)$ & $2.774(5)$ \\
$\mathrm{K}(1)-\mathrm{O}(2)$ & $2.950(3)$ & $2.927(4)$ \\
$\mathrm{K}(1)-\mathrm{O}(1)$ & $2.950(3)$ & $2.927(4)$ \\
$\mathrm{K}(1)-\mathrm{O}(1)$ & $2.954(1)$ & $2.929(1)$ \\
$\mathrm{K}(1)-\mathrm{O}(2)$ & $2.954(1)$ & $2.929(1)$ \\
$\mathrm{K}(1)-\mathrm{O}(2)$ & $3.179(3)$ & $3.182(5)$ \\
$\mathrm{K}(1)-\mathrm{O}(1)$ & $3.179(3)$ & $3.194(4)$ \\
$\mathrm{K}(1)-\mathrm{O}(2)$ & $3.187(4)$ & $3.694(4)$ \\
$\mathrm{K}(1)-\mathrm{O}(2)$ & $3.273(4)$ & \\
$\mathrm{M}(1)-\mathrm{O}(2)$ & $3.273(4)$ & \\
$\mathrm{M}(1)-\mathrm{O}(2)$ & $1.6890(1)-\mathrm{O}(1)$ & \\
\hline
\end{tabular}




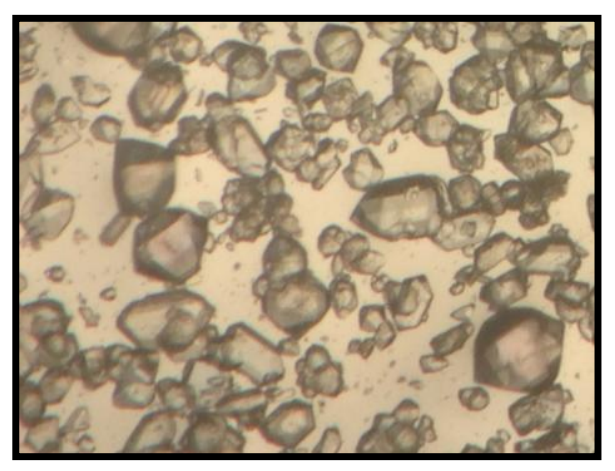

Figure 1. Optical image of a set of $\mathrm{KBaAsO}_{4}$ crystals.

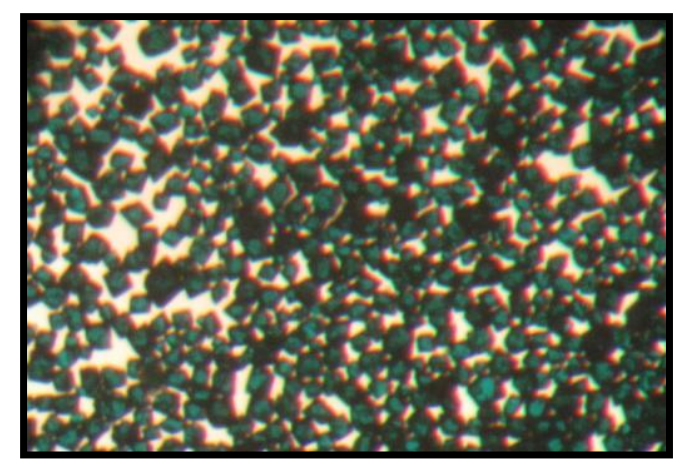

Figure 2. Optical image of a set of $\mathrm{KBaMnO}_{4}$ crystals. 


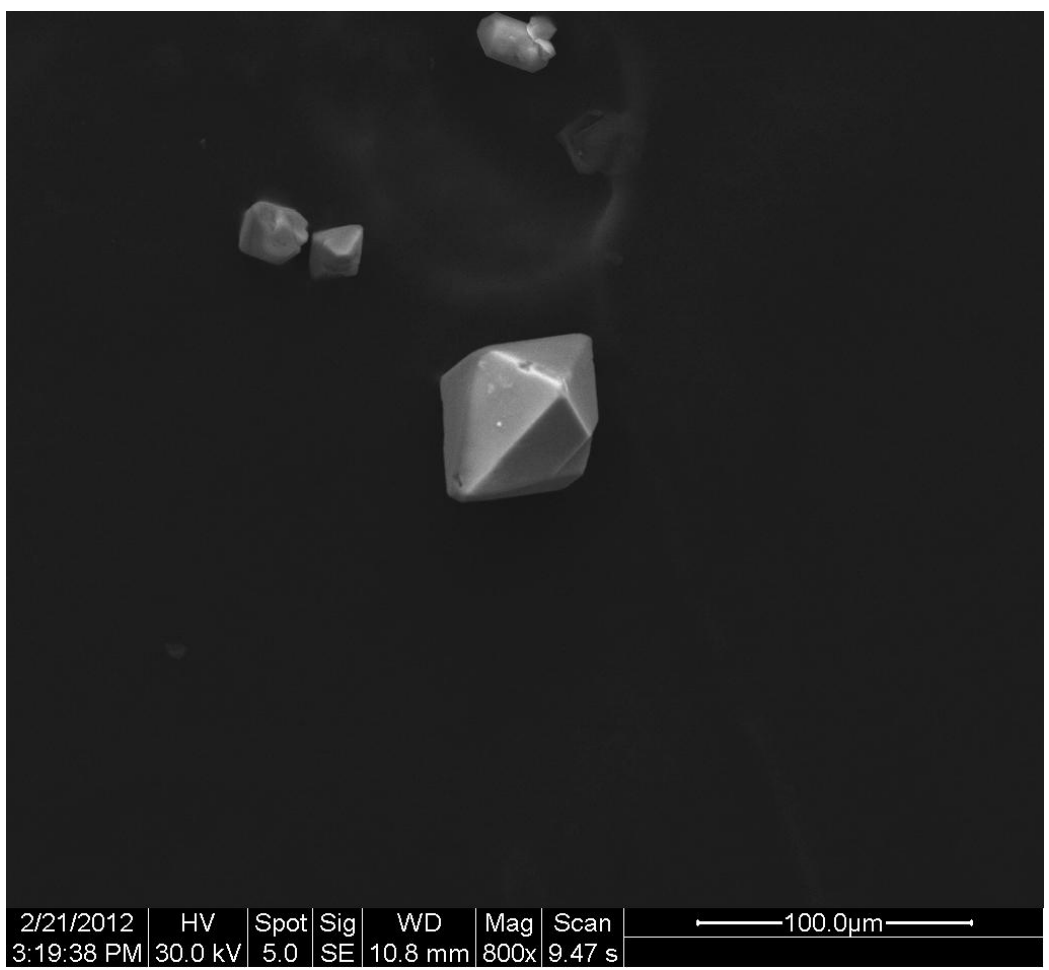

Figure 3. Scanning electron micrograph image of a $\mathrm{KBaMnO}_{4}$ crystal. 


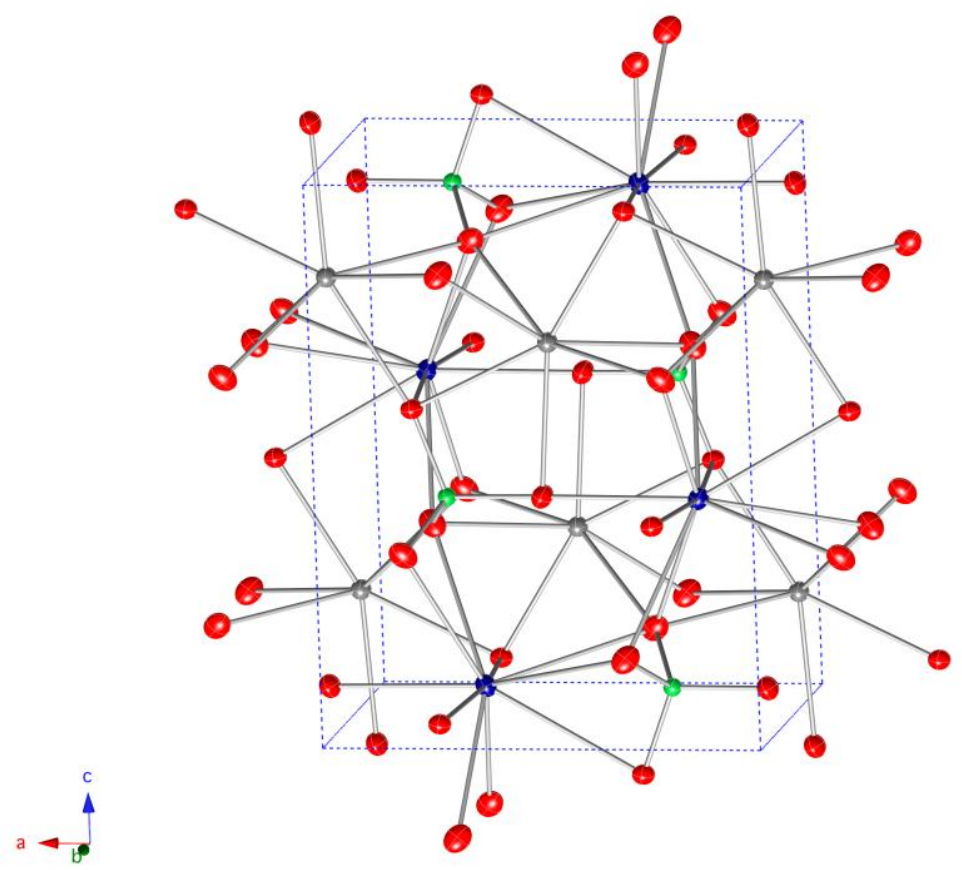

Figure 4. Unit cell of $\mathrm{KBaMO}_{4}(M=\mathrm{Mn}$, As), with oxygen atoms in red, manganese in green, barium atoms in grey, and potassium atoms in blue. All atoms are drawn as thermal ellipsoids at $50 \%$ probability. 


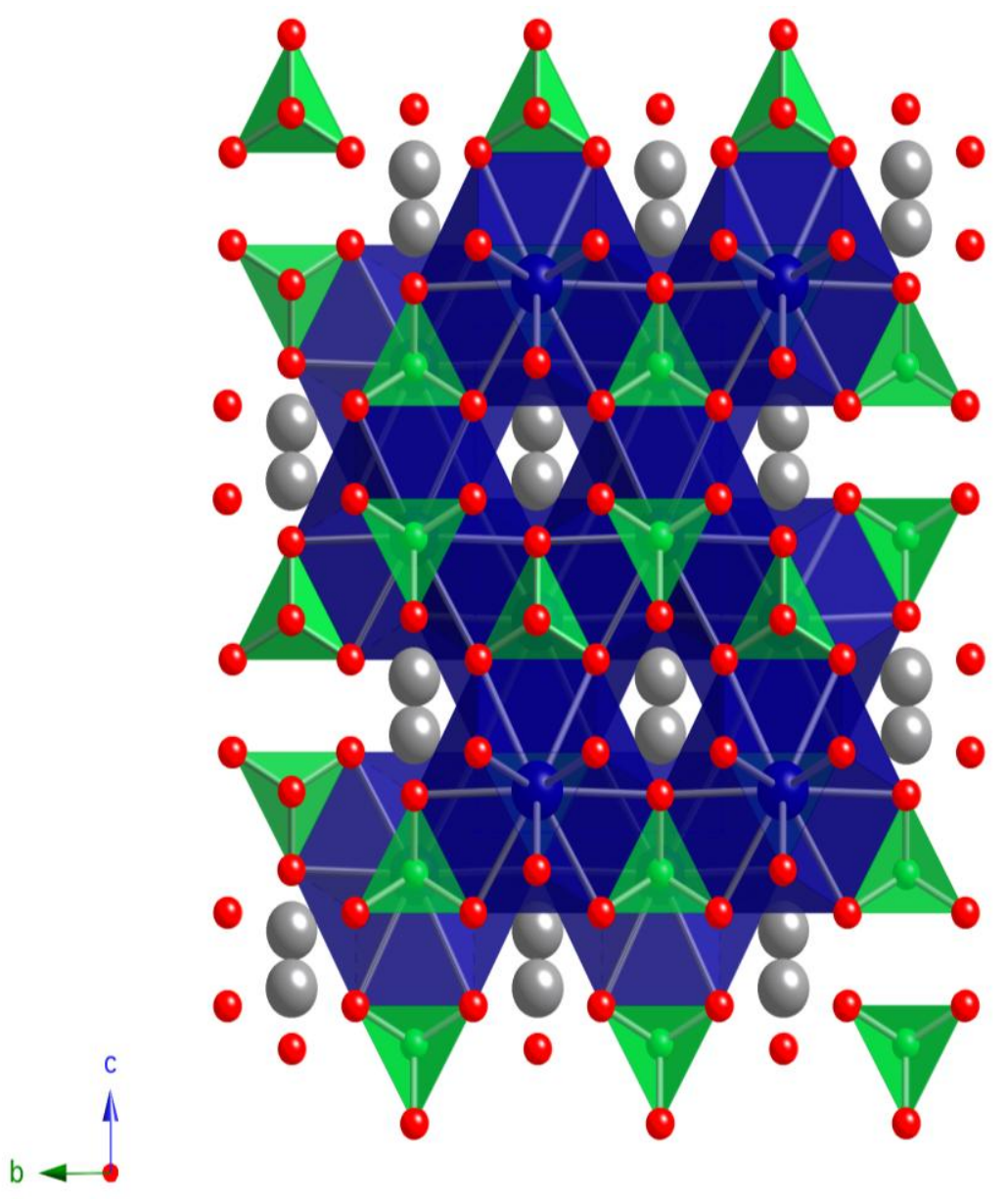

Figure 5. Extended view of the crystal structure of $\mathrm{KBa} \mathrm{O}_{4}(M=\mathrm{Mn}$, As), with oxygen atoms in red, $\mathrm{MO}_{4}$ tetrahedra in green, barium atoms in grey, and potassium coordination polyhedra shown down the $a$ axis. 


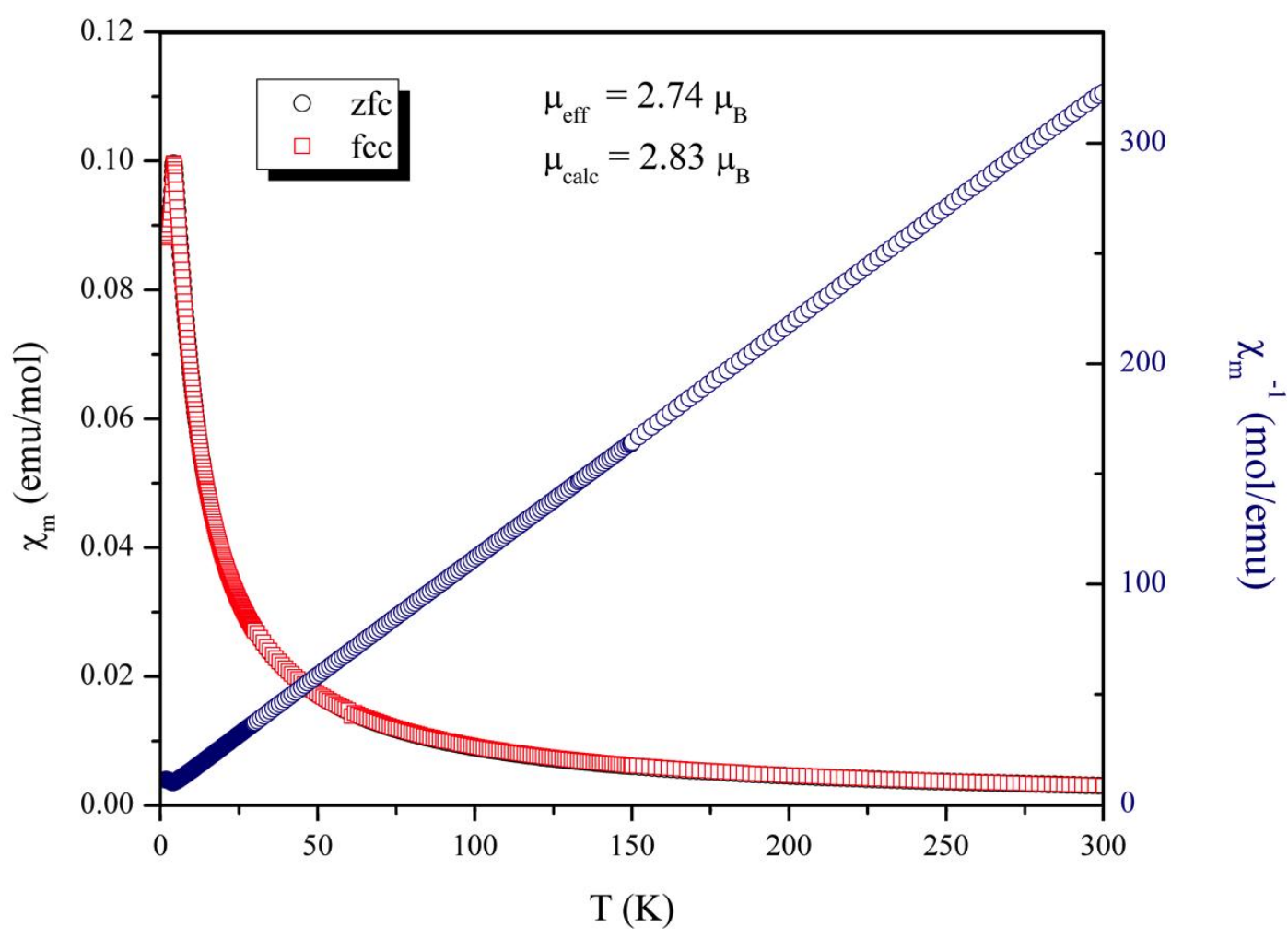

Figure 6. Temperature dependence of the molar magnetic susceptibility, $\chi_{\mathrm{m}}$, and inverse molar magnetic susceptibility, $1 / \chi_{\mathrm{m}}$, for $\mathrm{KBaMnO}_{4}$. 


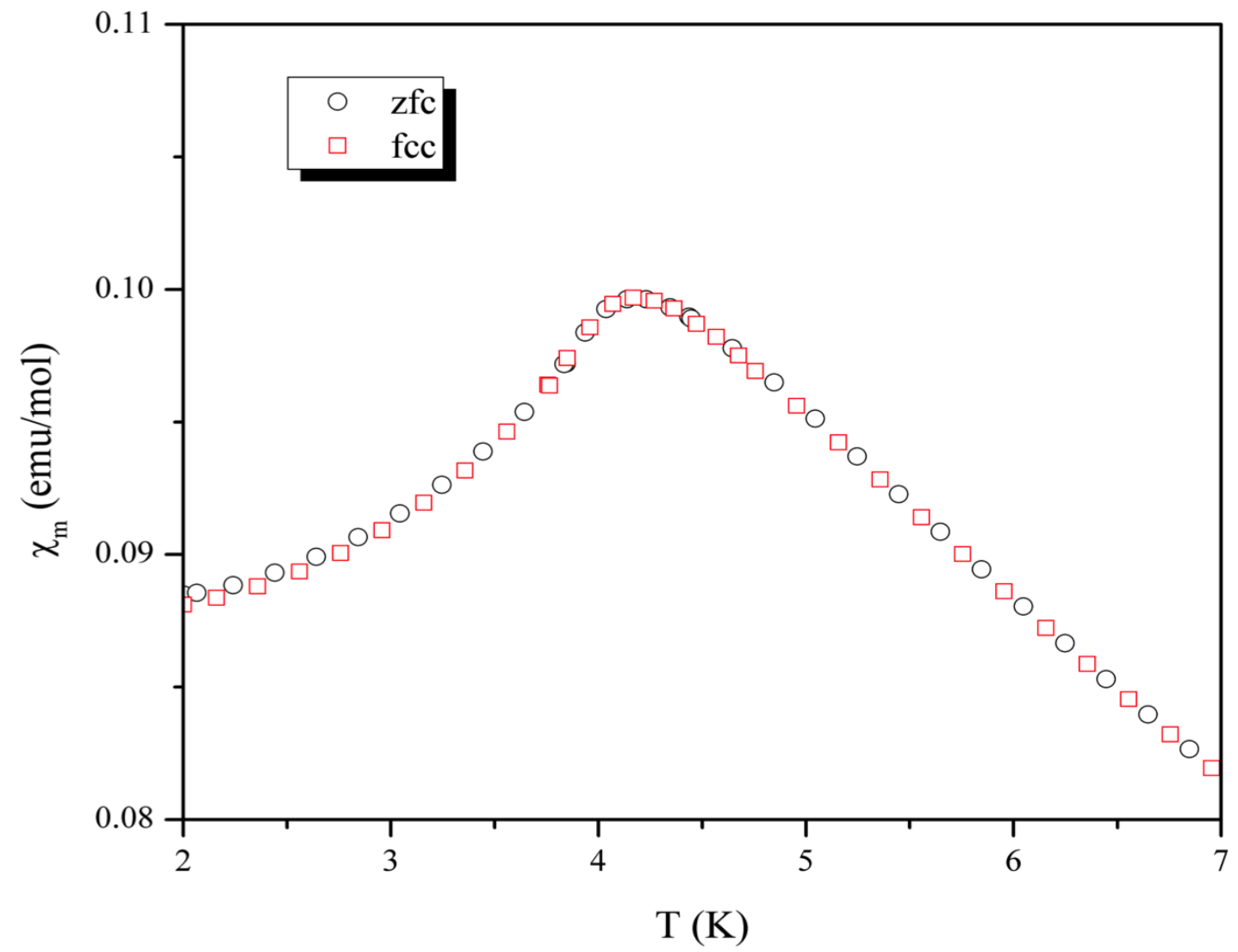

Figure 7. Low temperature region of the molar magnetic susceptibility, $\chi_{\mathrm{m}}$, and inverse molar magnetic susceptibility, $1 / \chi_{\mathrm{m}}$, for $\mathrm{KBaMnO}_{4}$. 

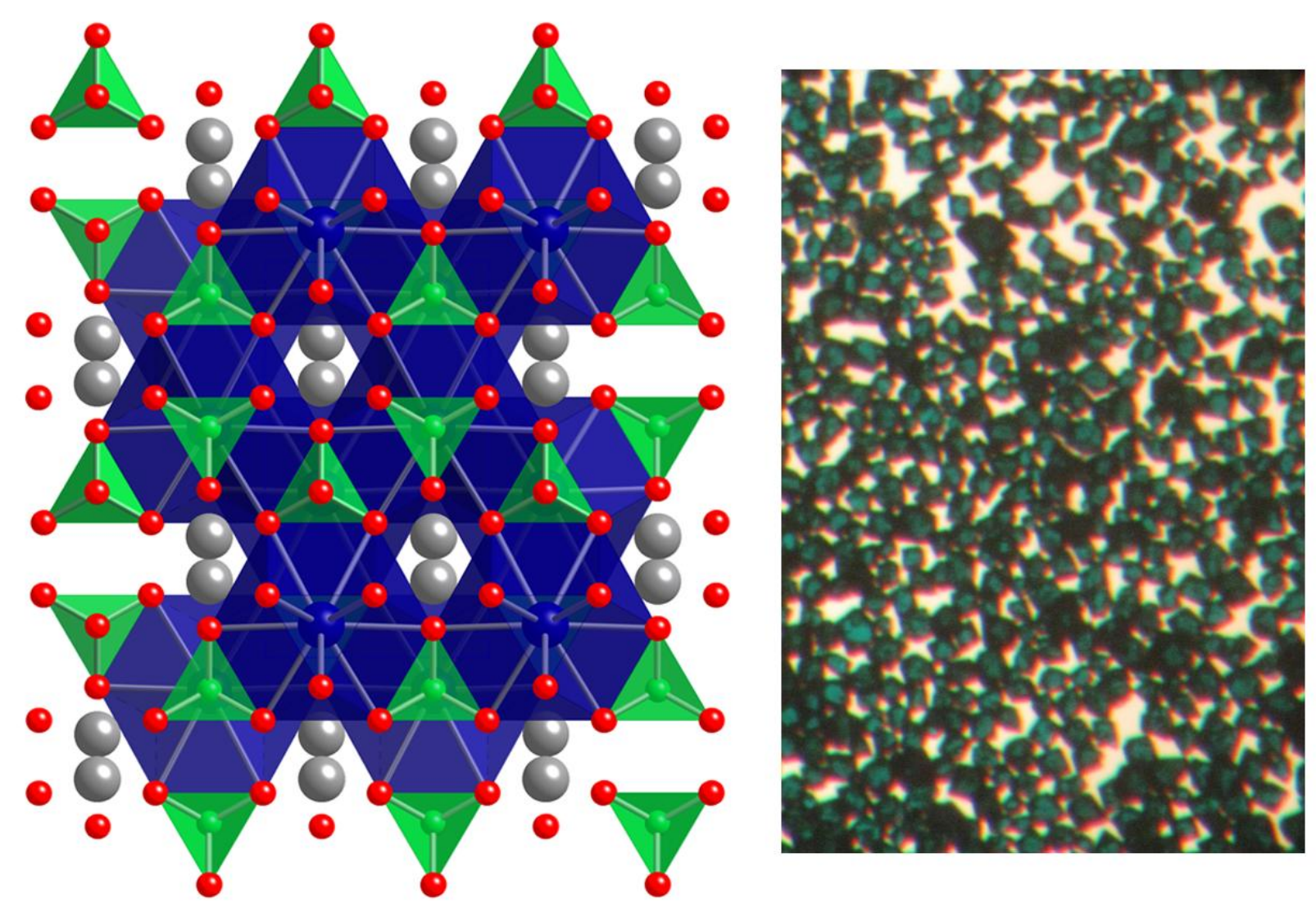